\title{
Role of acadesine in clinical myocardial protection
}

Acadesine (AICA riboside, 5-amino-1- $\beta$-D-ribofuranosyl-imidazole-4-carboxamide) is the prototype of a new class of compounds termed adenosine regulating agents. Acadesine is a purine nucleoside analogue that enters the myocyte and is immediately phosphorylated to ZMP (AICA ribotide), which is further metabolised to inosine monophosphate (an intermediate in the synthesis of adenosine triphosphate (ATP) and guanosine triphosphate) ${ }^{1-3}$ Claims that acadesine may serve as a substrate for ATP synthesis and result in repletion of myocardial ATP were supported by some studies ${ }^{4}$ and refuted by others. $^{5-8}$ Because acadesine may be a precursor in the synthesis of myocardial ATP it was proposed as a possible agent of myocardial protection during ischaemia, particularly because myocardial ATP depletion has been linked to cell death. ${ }^{910}$ Initial studies suggested that acadesine can accelerate repletion of the adenine nucleotide pool during reperfusion ${ }^{4}$ but subsequent reports did not. ${ }^{5-7}$

The myocardial protective properties of acadesine were shown in several in vivo models of myocardial ischaemia. Acadesine maintained contractile function and lessened the ST segment changes of the intramyocardial electrogram in dogs with pacing induced ischaemia. ${ }^{11}$ It also suppressed ischaemia and reperfusion induced arrhythmias. ${ }^{12} 13$ In various models of ischaemia acadesine improved blood flow to the ischaemic region causing preferential redistribution towards the subendocardium ${ }^{11}{ }^{13}$ and reducing the size of the evolving myocardial infarct. ${ }^{14}$

It has been suggested that the cardioprotective properties of acadesine may be mediated, at least in part, by increased release of adenosine in regions of ischaemia ${ }^{131516}$ because such regulation of the cardioprotective properties of acadesine was shown to be brought about by inhibition of endogenous adenosine formation ${ }^{16}$ or rapid breakdown of newly formed adenosine. ${ }^{17}$ It has been argued that because both acadesine ${ }^{1318}$ and adenosine $e^{1920}$ inhibit neutrophil activation, the adenosine-mediated protective effects of acadesine are attributable to attenuation of neutrophil activation which prevents neutrophil-dependent tissue injury.

Ely et al first suggested that adenosine has cardioprotective properties. ${ }^{21}$ These protective properties are well established, ${ }^{19-25}$ and they seem to mirror those of acadesine, ${ }^{5131426}$ which suggests that the cardioprotection afforded by acadesine may be mediated by increased release of local adenosine.

Because acadesine does not influence basal adenosine concentrations in non-ischaemic regions or have cardiac or haemodynamic effects in the absence of ischaemia, its actions have been defined as "event specific and site specific". This implies that acadesine works only in regions of ischaemia that are undergoing net ATP breakdown, thus providing protection where it is most needed. The search for a reliable therapeutic agent designed to reduce the consequences of irreversible ischaemia continues, and it is not surprising that acadesine, with its unique protective properties, is considered to be such an agent. Though these unique properties of acadesine (event specific and site specific) theoretically make it an attractive treatment in patients with acute myocardial infarction or unstable angina, its application in these conditions has not yet been tested. One argument against this potentially beneficial use is that acadesine must be present in the tissues before ischaemia and before irreversible myocardial injury has ensued. This may not be possible in patients who present hours after the initial symptoms. The same argument may not apply in those with unstable angina, because there is blood flow, albeit limited, to regions of ischaemia during episodes of angina and, in addition, collateral blood flow may also increase penetration of the drug into ischaemic zones. Because of its event and site specificity, acadesine administration does not produce systemic haemodynamic effects. ${ }^{11}{ }^{13}$ The haemodynamic effects associated with adenosine, such as hypotension and chronotropia ${ }^{23}$, are all but eliminated except when large doses of acadesine are given. ${ }^{27}$

Acadesine has been tried and tested in the setting of coronary artery bypass grafting (CABG) where both the onset and the duration of ischaemia can be predicted with a high degree of certainty. At least two clinical trials have attempted to evaluate the safety and the efficacy of acadesine in patients undergoing routine CABG. Initially Leung et al evaluated the effects of acadesine in a group of patients undergoing CABG. ${ }^{28}$ Two treatment groups received high or low dose acadesine (intravenous infusion) as well as St Thomas's cardioplegia solution with added acadesine. Acadesine offered no added protection against ischaemia in either treatment group as judged by electrocardiography, creatine kinase $\mathrm{MB}$ fraction (CK $\mathrm{MB}$ ), and transoesophageal Doppler criteria.

In a multicentre double blind prospective randomised study (unpublished data) acadesine (intravenous infusion of $0.1 \mathrm{mg} / \mathrm{kg} / \mathrm{min}$ for seven hours and $5 \mathrm{mg} / 1$ of cardioplegia solution) was compared with a placebo. Patients were further stratified into high risk group (unstable angina, age $>70$ years, previous CABG, ejection fraction $<30 \%$, and acutely failed angioplasty), and a group not at high risk. The incidence of myocardial infarction defined by $Q$ wave, necropsy, and $C K M B$ criteria was not significantly different between the treatment and placebo groups. The incidence of myocardial infarction (Q wave or necropsy criteria) was significantly lower in the high risk group (10\%) than in the group not at high risk $(19.7 \%, P=0.03)$. Analysis of the CK MB data showed no difference in the incidence of myocardial infarction. The inconsistency in the reported CK MB concentrations could reflect differences in the timing of sample collection at the various centres in the study.

Acadesine remains an interesting investigative tool for the evaluation of ischaemia and reperfusion injury that has yet to realise its potential as a therapeutic agent in clinical practice.

ABDUL M ALKHULAIFI WILF B PUGSLEY

Cardiothoracic Department

The Middlesex Hospital

Mortimer Street, London W1N 8AA 
1 Sabina RL, Kernstine KH, Boyd RL, Holmes EW, Swain JL. Metabolism of 5-amino-4-imidazolecarboxamide riboside in cardiac and skeleta muscle. F Biol Chem 1982;25:10178-83.

2 Sabina RL, Patterson D, Holmes EW. 5-amino-4-imidazolecarboxamide riboside (Z-riboside) metabolism in eukaryotic cells. $f$ Biol Chem 1985;260:6107-14.

3 Jimenez R, Gruber HE, Barankiewics J. AICA-riboside (5-amino-4-imidazolecarboxamide riboside) metabolism in human lymphocytes, red blood cells and platelets. Int $\mathcal{f}$ Purine Pyrimidine Res 1990;1:51-60.

4 Swain JL, Hines JJ, Sabina R, Holmes EW. Accelerated repletion of ATP and GTP pools in post-ischaemic canine myocardium using a precurso of purine de novo synthesis. Circ Res 1982;1:102.

5 Mitsos SE, Jolly JA, Lucchesi BR. Protective effects of AICA riboside in the globally ischaemic isolated cat heart. Pharmacology 1985;31:121-31.

6 Glower DD, Spratt JA, Newton JR, Rankin JS, Swain JL. Dissociation between early recovery of regional function and purine nucleotide content in post-ischaemic myocardium in the conscious dog. Cardiovasc Res 1987;21:328-36.

7 Mentzer RM, Ely SW, Lasley RD, Berne RM. The acute effects of AICAR on purine nucleotide metabolism and post-ischaemic cardiac function. F Thorac Cardiovasc Surg 1988;95:286-93.

8 Ambrosio B, Jacobus WE, Mitchell MC, Litt MR, Becker LC. Effects of ATP precursors on ATP and free ADP content and functional recovery of post-ischaemic hearts. Am f Physiol 1989;256:H560-H566.

9 Jennings RB, Hawkins HK, Lowe JE, Hill ML, Sherry Klotman BS, Reimer KA. Relation between high energy phosphate and lethal injury in myocardial ischaemia in the dog. Am f Pathol 1978;92:187-214.

10 Reimer KA, Jennings RB, Hill ML. Total ischaemia in dog hearts, in vitro: 2) High energy phosphate depletion and associated defects in energy metabolism, cell volume regulation, and sarcolemmal integrity. Circ Res 1981;49:901-11.

11 Young MA, Mullane KM. Progressive cardiac dysfunction with repeated episodes of pacing-induced ischaemia: protection by AICA riboside. $\mathrm{Am}$ f Physiol 1991;261:H1570-7.

12 Rosen MR, Molina-Viamonte V. Effects of AICA riboside on arrhythmias induced coronary occlusion and reperfusion in a feline model. Circulation 1990;82:111-5.

13 Grüber HE, Hoffer ME, McAllister DR, et al. Increased adenosine concentration in blood from ischaemic myocardium by AICA riboside: effects on flow, granulocytes and injury. Circulation 1989;80:1400-11.

14 McAllister DR, Engler R, Laikind P, Finley K, Grüber HE. Experimental infarct size reduction by a new mechanism: Augmented adenosine infarct size reduction by a new
release [abstr]. Clin Res $1987 ; 35: 303$.

15 Galiñanes M, Bullough D, Mullane KM, Hearse DJ. Sustained protection by acadesine against ischaemia and reperfusion-induced injury: studies in the transplanted rat heart. Circulation 1992;86:589-97.

16 Hori M, Kitakaze M, Takashima S. Beneficial effects of AICA-riboside on myocardial contractile and metabolic dysfunction following ischaemic injury in coronary microembolisation in dogs. Circulation 1991;84(suppl II): 305 .

17 Bullough DA, Fox MH, Mullane KM. Acadesine regulates adenosine to improve post-ischaemic function in the isolated heart. $7 \mathrm{Mol} \mathrm{Cell} \mathrm{Cardiol}$ improve post-isch

18 Levin RI, Ebrle MA, Mechetta P, Cornstein BN. Stimulation of adenosine release from human endothelial cells inhibits neutrophil function. Circulation 1990;82(suppl III): 177 .

19 Cronstein BN, Levin RI, Belanoff G, Weissmann G, Hirschhorn R. Adenosine: An endogenous inhibitor of neutrophil-mediated injury to endothelial cells. $\mathcal{F}$ Clin Invest 1986;78:760-70.

20 Cronstein BN, Kramer SB, Weissmann G, Hirschhorn R. Adenosine: A physiological modulator of superoxide anion generation by human neutrophils. F Exp Med 1989;158:1160-77.

21 Ely SW, Mentzer RM, Lasley RD, Lee BK, Berne RM. Functional and metabolic evidence of enhanced myocardial tolerance to ischaemia and reperfusion with adenosine. F Thorac Cardiovasc Surg 1985;90:549-56.

22 Olafsson B, Forman MB, Puett DW, et al. Reduction of reperfusion injury in the canine preparation by intracoronary adenosine: Importance of the endothelium and the no-flow phenomenon. Circulation 1987;76: endothelium

23 Belardinelli L, Linden J, Berne RM. The cardiac effects of adenosine. Prog Cardiovasc Dis 1989;32:73-97.

24 De Jong JW, Van der Meer P, Van Loon H, Owen P, Opie LH Adenosine as adjunct to $\mathrm{K}+$ cardioplegia: Effect on function, energ metabolism, and electrophysiology. F Thorac Cardiovasc Surg 1990; 100:445-54

$25 \mathrm{Li} \mathrm{Y}$, Kloner EA. The cardioprotective effects of ischaemic "preconditioning" are not mediated by adenosine receptors in rat hearts. Circulation 1993;87:1642-8

26 Bullough D, Fox M, Mullane $\mathrm{K}$. Acadesine regulates adenosine during early reperfusion to improve functional recovery in the postischaemic guinea pig heart [abstr]. Pharmacology 1990;52:85P.

27 Foley JM, Adams GR, Meyer RA. Utility of AICAR for metabolic studies is diminished by systemic effects in situ. Am $\mathcal{F}$ Physiol 1989;257:C488C94.

28 Leung JM, Stanley T, Metthew J, Curling P, Barash P. An initial multicentre, randomised controlled trial on the safety and efficacy of acadesine in patients undergoing coronary artery bypass surgery. Anesthesia sine in patients undergoing
Analgesia 1994;78:420-34. 